\title{
Thermal performance of cold storage in thermal battery for air conditioning
}

\author{
Jen-Jie Chieh, Shu-Ju Lin, Sih-Li Chen* \\ Department of Mechanical Engineering, National Taiwan University, No. 1 Roosevelt Rd. Sec 4, Taipei, Taiwan 106, ROC
}

Received 27 December 2002; received in revised form 15 August 2003; accepted 18 August 2003

\begin{abstract}
This article studies, experimentally and theoretically, the thermal performance of cold storage in thermal battery for air conditioning. Thermal battery utilizes the superior heat transfer characteristics of heat pipe and eliminates drawbacks found in the conventional thermal storage tank. Experimental investigations are first conducted to study the cold storage thermal performance in two experimental systems: the ratio of distance between heat pipes to outer diameter of heat pipe $\mathrm{W} / \mathrm{D}=6$ and 2. Different heat transfer mechanisms including nucleate boiling, geyser boiling and natural convection are identified in different experimental systems with various liquid fills. A theoretical model to determine the thermal characteristics of the thermal battery has also been developed. Comparisons of this theory with experimental data show good agreements in the nucleate boiling stage of cold storage process.
\end{abstract}

(C) 2003 Elsevier Ltd and IIR. All rights reserved.

Keywords: Air conditioning; Thermal storage; Nucleate boiling; Simulation; Experiment; Heat pipe

\section{Accumulation thermique à l'aide d'une batterie thermique : performance en application conditionnement d'air}

Mots clés : Conditionnement d'air ; Accumulation thermique ; Ébullition necléée ; Simulation ; Expérimentation ; Caloduc

\section{Introduction}

A number of thermal energy storage systems [1] have been considered and developed in recent years. Most of the energy storage systems utilize an active control method to store or release thermal energy. That is, in the system design of thermal storage, a pump is included to transfer thermal energy from a high temperature heat source to the thermal storage tank via flowing working fluid. To utilize the stored thermal energy, an

* Corresponding author. Tel.: +886-2-2363-1808; fax: +886-2-2363-1755.

E-mail address: slchen01@ccms.ntu.edu.tw (S.-L. Chen). electromagnetic valve is used under control to change flow path of the working fluid, so that energy stored in the storage tank is released to and used by a low temperature heat sink. There are two drawbacks found in such type of thermal storage systems. First, the need of an operation cost and power consumption of pump. The thermal storage shall be unworkable in case of a system failure. Second, change of the charge and discharge ability of the conventional storage systems is basically relied on the system piping design and therefore only two functions, i.e. energy storage and energy release, are available in its operating modes.

The objective of the present article is to provide a thermal battery [2] in which a passive type of control is adopted 


\begin{tabular}{|c|c|c|c|}
\hline \multicolumn{2}{|c|}{ Nomenclature } & \multirow{4}{*}{$\begin{array}{l}Q_{\mathrm{i}} \\
\dot{Q}_{\mathrm{o}} \\
q_{\mathrm{o}}^{*}\end{array}$} & \multirow{2}{*}{$\begin{array}{l}\text { thermal energy rate supplied to the thermal } \\
\text { battery (w) } \\
\text { cold storage rate of the thermal battery (w) }\end{array}$} \\
\hline$A$ & cross area of header $\left(\mathrm{m}^{2}\right)$ & & \\
\hline$A_{\mathrm{n}}$ & cross area of single vertical pipe $\left(\mathrm{m}^{2}\right)$ & & dimensionless cold storage flux of the thermal \\
\hline$A_{\mathrm{H}}$ & $\begin{array}{l}\text { surface area of all pipes insides the storing } \\
\text { chamber }\left(\mathrm{m}^{2}\right)\end{array}$ & & $\begin{array}{l}\text { battery, } \\
\left(S_{0}+S_{1}+h_{\mathrm{A}}+h_{\mathrm{EA}}\right) \dot{Q}_{0} /\left(A_{\mathrm{H}} \rho_{\mathrm{F}} v_{\mathrm{F}} h_{\mathrm{fg}}\right)\end{array}$ \\
\hline$A_{\mathrm{r}}$ & $\begin{array}{l}\text { surface area of all pipes insides heat pipes } \\
\left(\mathrm{m}^{2}\right)\end{array}$ & $\begin{array}{l}Q_{\mathrm{s}} \\
Q_{\mathrm{s}}^{*}\end{array}$ & $\begin{array}{l}\text { cumulative cold storage quantity }(\mathrm{J}) \\
\text { dimensionless cumulative cold storage }\end{array}$ \\
\hline$A_{\text {tank }}$ & cross area of the storing chamber $\left(\mathrm{m}^{2}\right)$ & & quantity, $\sum_{0}^{t / \Delta t} q_{\mathrm{o}}^{*} A_{\mathrm{H}} \Delta t^{*}$ \\
\hline$a$ & $\begin{array}{l}\text { gas constant of equation } \ln P=a-(b / T)- \\
c \ln T \text { (dimensionless) }\end{array}$ & $R_{\mathrm{v}}$ & $\begin{array}{l}\text { gas constant of equation } \mathrm{P}=\rho R_{v} T\left(\mathrm{Jk} \mathrm{g}^{-1}\right. \\
\left.\mathrm{K}^{-1}\right)\end{array}$ \\
\hline$b$ & $\begin{array}{l}\text { gas constant of equation } \ln P=a-(b / T)- \\
\operatorname{cln} T(\mathrm{~K})\end{array}$ & $\begin{array}{l}R_{\mathrm{t}} \\
r_{\mathrm{o}}\end{array}$ & $\begin{array}{l}\text { thermal resistance }\left(\mathrm{Kw}^{-1}\right) \\
\text { outer radius of heat pipe }(\mathrm{m})\end{array}$ \\
\hline $\mathrm{C}_{1}$ & $\begin{array}{l}\text { constant of entropy } i_{\mathrm{v}}=\mathrm{C}_{1}\left(T-T_{\mathrm{F}}\right)+d-e T \\
\left(\mathrm{Jkg}^{-1} \mathrm{~K}^{-1}\right)\end{array}$ & $\begin{array}{l}r_{\mathrm{i}} \\
S_{0}\end{array}$ & $\begin{array}{l}\text { inner radius of heat pipe }(\mathrm{m}) \\
\text { length of upper or lower connecting pipes }(\mathrm{m})\end{array}$ \\
\hline $\begin{array}{l}C_{\mathrm{p}} \\
c\end{array}$ & $\begin{array}{l}\text { specific heat }\left(\mathrm{Jkg}^{-1} \mathrm{~K}^{-1}\right) \\
\text { gas constant of equation } \ln P=a-(b / T)-\end{array}$ & $S_{1}$ & $\begin{array}{l}\text { length between the ice storage tank and the } \\
\text { exchanger }(\mathrm{m})\end{array}$ \\
\hline & $c \ln T$ (dimensionless) & $S_{\mathrm{c}}$ & ice radial thickness outsides pipe $(\mathrm{m})$ \\
\hline$D$ & diameter of header $(\mathrm{m})$ & $\Delta S_{\mathrm{c}}$ & ice radial thickness growth $(\mathrm{m})$ \\
\hline$D_{\mathrm{n}}$ & diameter of single pipe $(\mathrm{m})$ & $T$ & temperature $(\mathrm{K})$ \\
\hline$d$ & $\begin{array}{l}\text { constant of entropy } i_{\mathrm{v}}=\mathrm{C}_{1}\left(T-T_{\mathrm{F}}\right)+d-e T \\
\left(\mathrm{Jk} \mathrm{g}^{-1}\right)\end{array}$ & $\begin{array}{l}t \\
t^{*}\end{array}$ & $\begin{array}{l}\text { measurement time }(\mathrm{s}) \\
\text { dimensionless time, } F_{\mathrm{o}} P_{\mathrm{r}}\end{array}$ \\
\hline$e$ & $\begin{array}{l}\text { constant of entropy } i_{\mathrm{v}}=\mathrm{C}_{1}\left(T-T_{\mathrm{F}}\right)+d-e T \\
\left(\mathrm{Jk} \mathrm{g} \mathrm{g}^{-1} \mathrm{~K}^{-1}\right)\end{array}$ & $\begin{array}{l}\Delta t \\
\Delta t^{*}\end{array}$ & $\begin{array}{l}\text { time interval (s) } \\
\text { dimensionless time interval, }\end{array}$ \\
\hline $\begin{array}{l}F_{\mathrm{o}} \\
G\end{array}$ & $\begin{array}{l}\text { Fourier number, } \alpha_{\mathrm{F}} t /\left(S_{0}+S_{1}+h_{\mathrm{A}}+h_{\mathrm{EA}}\right)^{2} \\
\text { mass flow rate of refrigerant }\left(\mathrm{kg} \mathrm{s}^{-1}\right)\end{array}$ & & $v_{\mathrm{F}} \Delta t /\left(S_{0}+S_{1}+h_{\mathrm{A}}+h_{\mathrm{EA}}\right)^{2}$ \\
\hline$g$ & gravity acceleration $\left(\mathrm{m} \mathrm{s}^{-2}\right)$ & Gree & symbols \\
\hline$H_{\mathrm{sl}}$ & solidification latent heat of water $\left(\mathrm{Jk} \mathrm{g}^{-1}\right)$ & $\alpha$ & thermal diffusivity $\left(\mathrm{m}^{2} \mathrm{~s}^{-1}\right)$ \\
\hline $\begin{array}{l}H_{\mathrm{fg}} \\
h\end{array}$ & $\begin{array}{l}\text { vaporization enthalpy of refrigerant }\left(\mathrm{Jk} \mathrm{g}^{-1}\right) \\
\text { height of the freezer }(\mathrm{m})\end{array}$ & $\beta$ & $\begin{array}{l}\text { modified thermal expansion coefficient of } \\
\text { equation } \mathrm{d} \rho / \mathrm{d} T=-\beta\left(\mathrm{kg} \mathrm{m}^{-1} \mathrm{~K}^{-1}\right)\end{array}$ \\
\hline $\mathrm{h}_{0}$ & height difference between upper and lower & $\rho$ & density $\left(\mathrm{kg} \mathrm{m}^{-3}\right)$ \\
\hline$h_{\mathrm{A}}$ & $\begin{array}{l}\text { connecting pipes }(\mathrm{m}) \\
\text { height of liquid refrigerant at point } \mathrm{A}(\mathrm{m})\end{array}$ & $\varphi$ & $\begin{array}{l}\text { friction coefficient of turbulent flow } \\
\text { (dimensionless) }\end{array}$ \\
\hline $\begin{array}{l}h_{\mathrm{E}} \\
h_{\mathrm{EA}}\end{array}$ & $\begin{array}{l}\text { height of liquid refrigerant at point } \mathrm{E}(\mathrm{m}) \\
\text { height difference between point } \mathrm{A} \text { and } \mathrm{E}(\mathrm{m})\end{array}$ & $v$ & $\begin{array}{l}\text { kinematic viscosity of liquid refrigerant }\left(\mathrm{m}^{2}\right. \\
\left.\mathrm{s}^{-1}\right)\end{array}$ \\
\hline$h_{\mathrm{w}}$ & $\begin{array}{l}\text { heat transfer coefficient of water }\left(\mathrm{wm}^{-2}\right. \\
\left.\mathrm{k}^{-1}\right)\end{array}$ & $\varsigma_{V}$ & $\begin{array}{l}\text { kinematic viscosity of vapor refrigerant }\left(\mathrm{m}^{3}\right. \\
\left.\mathrm{kg}^{-1}\right)\end{array}$ \\
\hline$h_{\mathrm{r}}$ & $\begin{array}{l}\text { heat transfer coefficient of refrigerant }\left(\mathrm{wm}^{-2}\right. \\
\left.\mathrm{k}^{-1}\right)\end{array}$ & $\theta$ & $\begin{array}{l}\text { temperature difference between the } \\
\text { solidification temperature of PCM and the }\end{array}$ \\
\hline$h_{\mathrm{fg}}$ & vaporization enthalpy of refrigerant $\left(\mathrm{Jk} \mathrm{g}^{-1}\right)$ & & refrigerant temperature insides pips $(\mathrm{K})$ \\
\hline & $\begin{array}{l}\text { Jakob number, } C_{\mathrm{P}, \mathrm{F}}\left(T_{\mathrm{F}}-T_{\mathrm{s}}\right) / h_{\mathrm{fg}} \\
\text { conductivity }\left(\mathrm{wm}^{-1} \mathrm{~K}^{-1}\right)\end{array}$ & Subs & ipts \\
\hline$L$ & $\begin{array}{l}\text { water height difference during the } \\
\text { measurement interval (m) }\end{array}$ & $\begin{array}{l}\text { A } \\
\mathrm{c}\end{array}$ & $\begin{array}{l}\text { refrigerant at position } \mathrm{A} \\
\text { ice }\end{array}$ \\
\hline$L_{\mathrm{H}}$ & length of single vertical pipe (m) & $\mathrm{E}$ & refrigerant at position $\mathrm{E}$ \\
\hline$M$ & weight of water in the storage tank $(\mathrm{kg})$ & $\mathrm{F}$ & refrigerant at position $\mathrm{F}$ \\
\hline$m$ & $\begin{array}{l}\text { numbers of measurement point insides the ice } \\
\text { storage tank (dimensionless) }\end{array}$ & $\begin{array}{l}\mathrm{g} \\
\mathrm{H}\end{array}$ & $\begin{array}{l}\text { refrigerant vapor } \\
\text { refrigerant at position } \mathrm{H}\end{array}$ \\
\hline$m$ & mass flow rate of the brine $\left(\mathrm{kg} \mathrm{s}^{-1}\right)$ & in & brine inlet \\
\hline$n$ & $\begin{array}{l}\text { numbers of vertical pipes insides the storing } \\
\text { chamber (dimensionless) }\end{array}$ & $\begin{array}{l}1 \\
\text { out }\end{array}$ & $\begin{array}{l}\text { brine } \\
\text { brine outlet }\end{array}$ \\
\hline$P$ & pressure $\left(\mathrm{kg} \mathrm{m}^{-2}\right)$ & $\mathrm{s}$ & pipe wall \\
\hline $\operatorname{Pr}$ & Prandtl number, $v_{\mathrm{F}} / \alpha_{\mathrm{F}}$ & $\mathrm{w}$ & water \\
\hline
\end{tabular}


to eliminate drawbacks found in the conventional thermal storage systems and no pump and electromagnetic valve are required. Moreover, apart from storing and releasing energy, the thermal battery also allows operation of energy supply side and energy use side at the same time. The thermal battery, as shown in Fig. 1, mainly includes an energy storage tank and heat pipe loops. The energy storage tank is filled with phase change medium (PCM). The heat pipe loops include three parts, namely, a group of parallel heat pipes vertically disposed inside the energy storage tank, vertical high-temperature heat pipes and vertical low-temperature heat pipes separately located at outside of the tank.

Fig. 1a shows the function in which the thermal battery operates to store thermal energy. When an amount of low temperature flowing fluid flows into low-temperature heat exchanger in a direction as shown by the arrows in Fig. 1a, thermal energy contained in fluid is transferred to the vapor inside the vertical low-temperature heat pipes. The vapor having released thermal energy becomes liquid, which flows downward due to its gravity into the lower horizontal pipe. The liquid working fluid inside the storage tank becomes boiled and absorbs thermal energy to solidify the phase change medium from liquid to solid in the energy storing cells. The boiled vapor flows upward along inner wall surfaces of the vertical heat pipes and then the low-temperature heat pipe to complete one cycle of flow. Fig. 1b shows

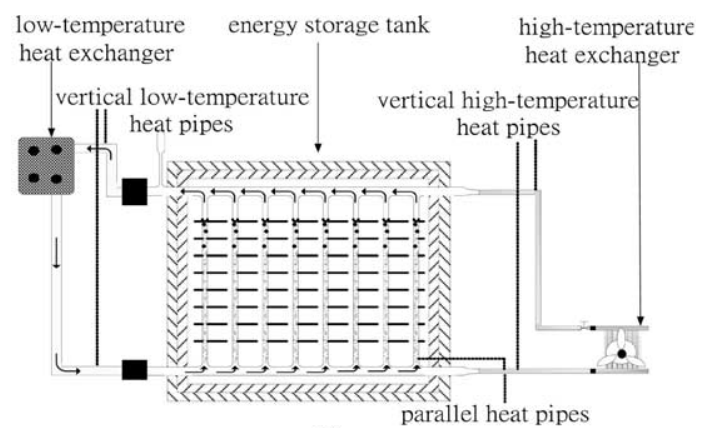

(a)

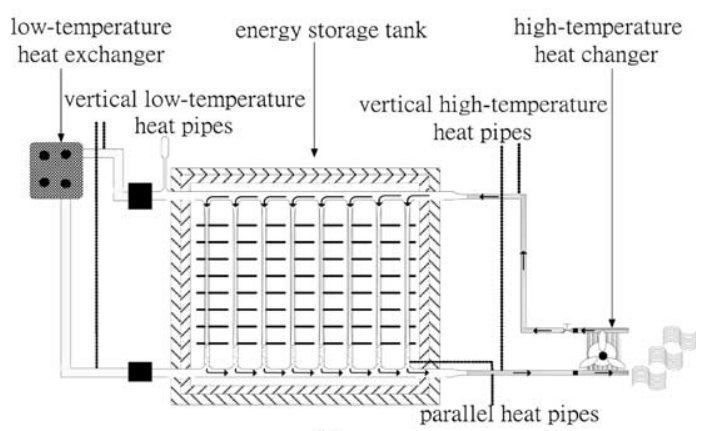

(b)

Fig. 1. Thermal battery for air conditioning (a) charge mode (b) discharge mode. the manner in which the thermal battery operates to release thermal energy. When high temperature air flows through high-temperature heat exchanger in a direction as shown by the arrows in Fig. 1b, the liquid inside the vertical high-temperature heat pipes becomes boiled and produces vapor, which flows upward into the vertically paralleled heat pipes in the energy storage tank. Then the vapor working fluid condenses and releases heat to melt solid phase change medium into liquid in the energy storing cells. The condensed liquid flows downward along inner wall surfaces of the vertical heat pipes to complete another cycle.

The mention of closed loop thermosyphon heat pipes in literature dated back decades ago. McDonald et al. [3] conducted experimental study of two-phase thermosyphon loop, suggesting that liquid level differences, fill ratio, operating pressure and temperature of heat source and heat sink affected the efficiency of loop performance. Manlio and Jai [4] simulated the thermal energy transport of a two-phase loop and found that the temperature difference between condenser and evaporator during transport of thermal energy was small. Chen et al. [5] conducted experimental study on single-loop, rectangular and separate heat pipes with uniform cross area and proposed that under stable state, evaporation, condensation and overall thermal conductivity of the system increased along with increase of thermal flow and when fill ratio was less than $35 \%$, superheat occurred.

This paper conducts experimental investigations and theoretical analysis on the charge characteristics of cold storage in thermal battery. In two experimental systems with the ratio of distance between heat pipes to outer diameter of heat pipe $\mathrm{W} / \mathrm{D}=6$ and 2 , flow patterns are identified in different experimental systems with various liquid fills. This paper also probes the effect of the fill level in thermal battery on the cold storage rate and cumulative cold storage quantity. A theoretical model is also developed to analyze thermal characteristics of cold storage in the thermal battery.

\section{Experimental investigations}

Two sets of experiment system were designed by the size of energy storage tank, $30 \times 12 \times 65 \mathrm{~cm}$ with the ratio of distance between heat pipes to outer diameter of radial fins heat pipe $\mathrm{W} / \mathrm{D}=6$ and 4 respectively, as shown in Fig. 2. At the front of the tank, tempered glass replaces the stainless steel material to allow the observation of ice layer formation. The multi-loop heat pipes were made of ASTM B88 L-type copper tubes.

The measurement system consists of T-type thermocouples, flow meter, pressure gauge, electronic scale, liquid level indicator, digital camera, height indicator. The measured physical quantities include brine inlet/ outlet temperature of heat exchanger, brine cycle flow 
rate, temperature and pressure of refrigerant in and out of ice storage tank, variation of water temperature in ice storage tank, liquid refrigerant level in ice storage tank, change of water level inside energy storing chamber and surrounding temperature.

The thermal energy rate supplied to thermal battery $Q_{\mathrm{i}}$ is computed from the temperature difference at inlet

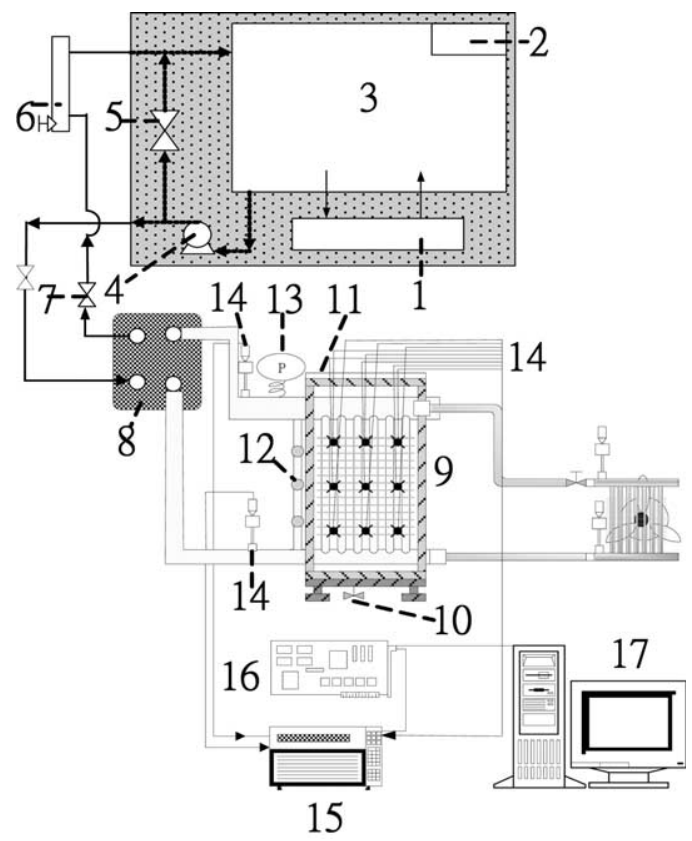

Fig. 2. Experimental systems, equipment, and measurement systems: 1 . chiller, 2. resistance heater, 3. thermostatic tank, 4. brine cycle pump, 5 . bypass valve, 6 . purgmeter, 7. valve, 8 . heat exchanger, 9. energy storage tank, 10. drain hole, 11. upper cover, 12. liquid level indicator, 13. pressure gauge, 14. thermocouples, 15. data recorder, 16.GPIB card, 17. monitor. and outlet of the brine flowing through the low temperature heat exchanger:

$\dot{Q}_{\mathrm{i}}=\dot{m} C_{\mathrm{pl}}\left[T_{\text {out }}(t)-T_{\mathrm{in}}(t)\right]$

Cold storage rate of the thermal battery $Q_{\mathrm{o}}$ is the rate of latent and sensible heat storage of water in the energy storing chamber during a period of time. The former may be calculated from the thickness of ice layer by observing the variation of water level in energy storing chamber; the latter may be obtained based on measurements of temperatures of water in energy storing chamber. The water temperature at various points of energy storing chamber is $T_{\mathrm{w}}$, and the average temperature of measurement points is $\sum T_{\mathrm{w}} / m$, where $m$ is the number of measurement points in energy storing chamber. Thus cold storage rate of the thermal battery, $Q_{\text {o }}$ can be expressed as

$$
\begin{aligned}
\dot{Q}_{\mathrm{o}}= & M C_{\mathrm{pw}}\left[\sum T_{\mathrm{w}}(t) / m-\sum T_{\mathrm{w}}(t-\Delta t) / m\right] / \Delta t \\
& +\rho_{w} \rho_{c} /\left(\rho_{w}-\rho_{c}\right) L A_{\tan k} H_{s l} / \Delta t
\end{aligned}
$$

Therefore the cumulative cold storage quantity in these experiments $Q_{\mathrm{s}}$ is the summation of cold storage rate for each time interval in thermal battery:

$Q_{\mathrm{s}}=\int_{0}^{t} \dot{Q}_{\mathrm{o}} \mathrm{d} t=\sum_{0}^{t / \Delta t} \dot{Q}_{\mathrm{o}} \Delta t$

According to the uncertainty analysis proposed by ISO standard [6], the uncertainties of maximum thermal energy rate and cold storage rate under high fill level are $\pm 1.18 \mathrm{kJs}^{-1}( \pm 7.67 \%)$ and $\pm 1.47 \mathrm{kJs}^{-1}( \pm 10.64 \%)$, respectively.

(a)multi-loop heat pipe model

(b)cold storage model

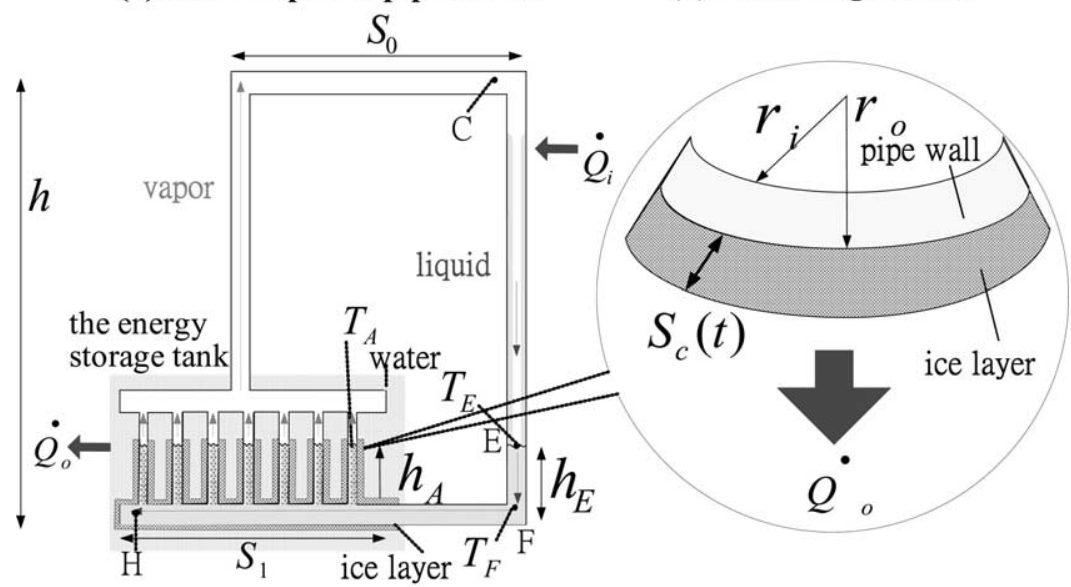

Fig. 3. Theoretical model: (a) multi-loop heat pipe model, (b) cold storage model. 


\section{Theoretical model}

The theoretical model of thermal battery comprises two parts - multi-loop heat pipe model and cold storage model as depicted in Fig. 3 and described as follows.

\subsection{Multi-loop heat pipe model}

As shown in Fig. 3a, there are two liquid-vapor interfaces ( $\mathrm{A}$ and $\mathrm{E}$ ) and assuming it is in thermal equilibrium state and the section of heat pipe between evaporator and condenser is adiabatic. In this figure $T_{\mathrm{F}}$ represents the average temperature of the entire loop, $T_{\mathrm{A}}$ is the local temperature of level $\mathrm{A}$ and $T_{\mathrm{E}}$ is the local temperature of level E. The entire system contains the following physical phenomena: nucleate boiling of liquid between $\mathrm{H}$ and $\mathrm{A}$; superheating of vapor between $\mathrm{A}$ and $\mathrm{B}$; adiabatic flow of vapor from $\mathrm{B}$ to $\mathrm{C}$; condensation of vapor between $\mathrm{C}$ and $\mathrm{E}$; sub cooling of liquid between $\mathrm{E}$ and $\mathrm{F}$; and adiabatic flow of liquid from $\mathrm{F}$ to $\mathrm{H}$.

The following assumptions are made based on the work of Manlio and Jai [4]. Refrigerant flow is onedimensional; the liquid-vapor phases of refrigerant are totally separated; the compression property of gaseous refrigerant is negligible; evaporation and condensation occur exactly at A and E; and the two-phase interfaces $\mathrm{A}$ and $\mathrm{E}$ are in thermal equilibrium.

Four governing equations of multi-loop heat pipe model are derived from the momentum and energy conservation equations. Eqs. (4) and (5) are obtained from conservation of momentum. The momentum equation for vapor refrigerant from $\mathrm{A}$ to $\mathrm{E}$ is

$$
\begin{aligned}
& \frac{R_{\mathrm{V}}^{2} G^{2}}{2 n}\left[\frac{1}{A^{2}}\left(\frac{T_{\mathrm{E}}}{P_{\mathrm{E}}}\right)^{2}-\frac{1}{A_{n}^{2}}\left(\frac{T_{\mathrm{A}}}{P_{\mathrm{A}}}\right)^{2}\right]+n g h_{\mathrm{EA}} \\
& +n R_{\mathrm{V}} T_{\mathrm{E}} G \ln \left(\frac{P_{\mathrm{E}}}{P_{\mathrm{A}}}\right)+n \frac{0.8106}{1.2732^{\varphi}} v_{\mathrm{VE}}^{\varphi}\left(\frac{G}{n}\right)^{2-\varphi}\left(\frac{R_{\mathrm{V}} T_{\mathrm{E}}}{P_{\mathrm{E}}}\right)^{2-\varphi} \\
& \times\left[\frac{\left(n S_{0}+\frac{n S_{1}}{2}\right)+2 n\left(h-h_{\mathrm{E}}\right)+n\left(h_{\mathrm{EA}}-h_{0}\right)}{D^{5-\varphi}}\right]=0
\end{aligned}
$$

The first term in Eq. (4) is the inertia force, the secondary term represents the gravitational force, the third term indicates the pressure force, and the last term shows the pipe friction loss of turbulent flow obtained from the Moody chart.

The momentum equation for liquid refrigerant from $\mathrm{E}$ to $\mathrm{A}$ is

$$
\begin{aligned}
& n\left[\left(P_{\mathrm{A}}-P_{\mathrm{E}}\right)-0.5 g \beta h_{\mathrm{E}}\left(T_{\mathrm{A}}-T_{\mathrm{E}}\right)+0.5 g \beta T_{\mathrm{A}} h_{\mathrm{EA}}\right. \\
& \left.-g \rho_{\mathrm{F}} h_{\mathrm{EA}}-0.5 g \beta T_{\mathrm{F}} h_{\mathrm{EA}}\right]+40.744 v_{\mathrm{F}} \\
& \times\left(\frac{n S_{0}+\frac{n S_{1}}{2}+n h_{\mathrm{E}}}{D^{4}}+\frac{n\left(h_{\mathrm{E}}-h_{\mathrm{EA}}\right)}{D_{n}^{4}}\right) G=0
\end{aligned}
$$

The first term in Eq. (5) expresses the combined pressure force and gravitational force of the control volume. The second term shows the pipe friction loss of laminar flow obtained from the Moody chart. It should be noted that inertia force for liquid does not show up in Eq. (5). This is due to the fact that the liquid inertia force can be neglected for the equal velocity at the two boundaries of the control volume.

On the basis of conservation of energy, the energy equation for liquid refrigerant from $\mathrm{E}$ to $\mathrm{A}$ can be expressed as

$\left[\left(C_{1}-e\right) G T_{\mathrm{A}}-\left(C_{1}-e\right) G T_{\mathrm{E}}\right]-G g h_{\mathrm{EA}}=\dot{Q}_{\mathrm{i}}-\dot{Q}_{\mathrm{o}}$

The first term in the RHS of Eq. (6) is the liquid enthalpy difference among the control surface, while the second term represents the gravitational energy. Those should be equal to the net input power as shown in the LHS of Eq. (6). The energy equation for liquid refrigerant from $\mathrm{H}$ to $\mathrm{A}$ can be derived as

$\left[\left(C_{1}-e\right) G T_{A}+\left(d-e T_{\mathrm{A}}\right) G\right]+G g\left(h_{\mathrm{E}}-h_{\mathrm{EA}}\right)=\dot{Q}_{i}$

In Eq. (7), the summation of liquid enthalpy and gravitational energy should be equal to the thermal energy rate supplied to the thermal battery.

\subsection{Cold storage model}

Cold storage rate is not constant and decreases as the ice layer thickness outside the heat pipes become thicker. The cold storage model, as shown in Fig. 3b, is needed to couple with multi-loop heat pipe model for simulation cold storage process. The cold storage rate is calculated by the ratio of the difference in temperature between working fluid, $T_{\mathrm{A}}$, and water, $T_{\mathrm{w}}$, to the entire thermal resistance, $R_{\mathrm{t}}$ :

$\dot{Q}_{\mathrm{o}}=\frac{T_{\mathrm{w}}-T_{\mathrm{A}}}{R_{\mathrm{t}}}$

The temperature of working fluid $T_{\mathrm{A}}$ is calculated from Eqs. (4)-(7), and the temperature of water $T_{\mathrm{w}}$ is determined from sensible heat storage part of cold storage rate: 


$$
\begin{aligned}
T_{\mathrm{w}}(t) & =T_{\mathrm{w}}(t-\Delta t) \\
& +\left[2 \pi \Delta S_{\mathrm{c}}(t) L_{\mathrm{H}} \rho_{\mathrm{c}}\left(H_{\mathrm{sl}}+T_{\mathrm{w}}(t-\Delta t)\right)-\dot{Q}_{\mathrm{o}}\right] / \\
& \left\{\left[M-2 \pi\left(S_{\mathrm{c}}(t-\Delta t)-r_{\mathrm{o}}\right) L_{\mathrm{H}} \rho_{\mathrm{c}}\right] C_{\mathrm{pw}}\right\}
\end{aligned}
$$

The overall thermal resistance, $R_{\mathrm{t}}$, consists of the thermal resistance of natural convection of water, ice layer conduction, pipe wall conduction, and nucleate boiling of working fluid. Among them, the thermal resistance of ice layer conduction is far larger than that of others. Therefore the overall thermal resistance is nearly equal to the thermal resistance of ice layer conduction.

$$
\begin{aligned}
R_{\mathrm{t}} & =\frac{1}{h_{\mathrm{w}} A_{\mathrm{H}}}+\frac{\ln \left(S_{\mathrm{c}} / r_{\mathrm{o}}\right)}{2 \pi k_{\mathrm{c}} L_{\mathrm{H}}}+\frac{\ln \left(r_{\mathrm{o}} / r_{\mathrm{i}}\right)}{2 \pi k_{\mathrm{s}} L_{\mathrm{H}}}+\frac{1}{h_{\mathrm{r}} A_{\mathrm{r}}} \\
& \approx \frac{\ln \left(S_{\mathrm{c}} / r_{\mathrm{o}}\right)}{2 \pi k_{\mathrm{c}} L_{\mathrm{H}}}
\end{aligned}
$$

Ice layer thickness outside pipe, $S_{\mathrm{c}}$ is calculated from the Bogdan and Horbaniuc model [7]:

$$
\begin{aligned}
\frac{k_{\mathrm{s}} \theta}{H_{\mathrm{sl}} \rho_{\mathrm{c}} r_{\mathrm{o}}^{2}} t= & \frac{1}{2}\left(1+\frac{S_{\mathrm{c}}(t)}{r_{\mathrm{o}}}\right)^{2} \ln \left(1+\frac{S_{\mathrm{c}}(t)}{r_{\mathrm{o}}}\right)-\frac{1}{4} \\
& \times\left[\left(1+\frac{S_{\mathrm{c}}(t)}{r_{\mathrm{o}}}\right)+1\right]
\end{aligned}
$$

Non-linear coupling equations of the multi-loop heat pipe model [Eqs. (4)-(7)], the cold storage model [Eqs. (8)-(11)] and the correlation between refrigerant pressure and temperature, which is $\ln P=a-(b / T)-c \ln T$, are numerically solved by steepest descent method.

\section{Results and discussion}

In the experiment, influences of the ratio of distance between heat pipes to outer diameter of heat pipe (W/D) was carried out in two systems, i.e. one experiment system with the ratio $\mathrm{W} / \mathrm{D}=6$ and the other with the ratio $\mathrm{W} / \mathrm{D}=2$. To examine the effect of the fill level of liquid refrigerant in energy storage tank on cold storage phenomenon of thermal battery, system performance was analyzed under liquid level of $30 \mathrm{~cm}, 40 \mathrm{~cm}$ and $50 \mathrm{~cm}$ respectively. It is observed that ice layers in the thermal battery with the ratio $(\mathrm{W} / \mathrm{D}=6)$ cannot reach the full ice storage after $3 \mathrm{~h}$ at Refrigerant 22 operating temperature of $-6{ }^{\circ} \mathrm{C}$. There still remained approximately quarter of the PCM as water state, while at the thermal battery with the ratio $(W / D=2)$ ice formed among the vertical heat pipes were completely adjoined in 15-25 min for any liquid level.

For the case of cold storage in the thermal battery with large ratio of $\mathrm{W} / \mathrm{D}$, the temperature histories of vapor at the upper location and liquid at the lower header are shown in Fig. 4a. In the initial stage of cold storage, both the liquid and vapor temperatures dropped steeply initially, but subsequent temperatures of liquid and vapor variation differ. Vapor temperature kept saturated and liquid temperature rose from subcooling to saturation. Nucleate boiling occurs inside the vertical tubes. In the secondary stage of cold storage, liquid temperature keeps saturated and vapor temperature oscillates periodically. The flow pattern in the thermal battery becomes a large slug oscillating in the liquid. Geyser boiling is the heat transfer mechanism in this flow pattern. In the last stage of cold storage, both the liquid and vapor temperatures remain constant.

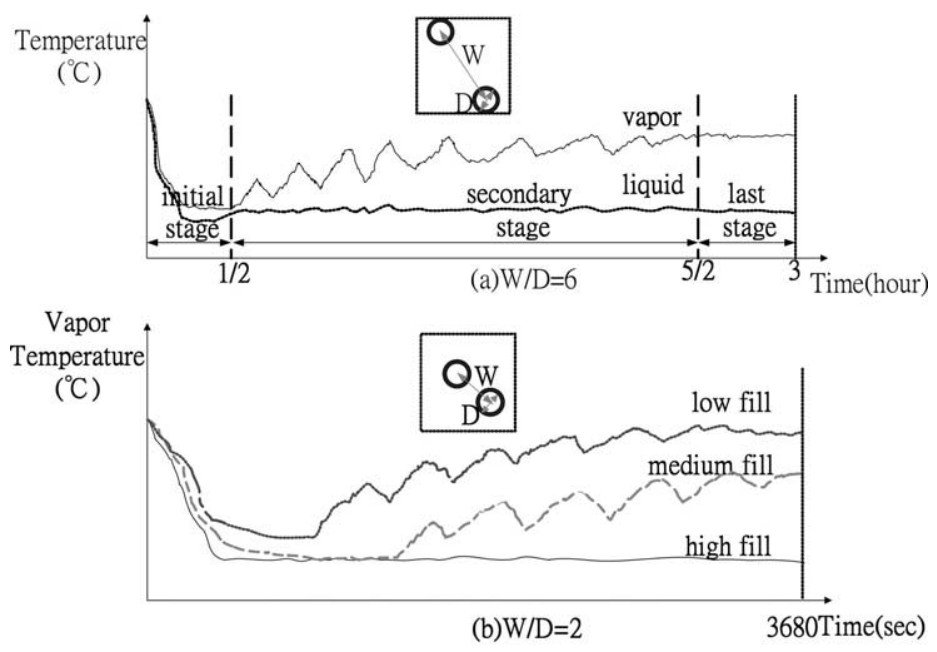

Fig. 4. Flow phenomena in the thermal battery: (a) vapor and liquid temperature profiles for $\mathrm{W} / \mathrm{D}=6$ at high fill level $(50 \mathrm{~cm})$, (b) vapor temperature profiles for $\mathrm{W} / \mathrm{D}=2$ at low, medium and high fill levels $(30,40$, and $50 \mathrm{~cm})$. 
Natural convection in liquid and heat pipe wall becomes the dominated heat transfer mechanism.

For the case of cold storage in the thermal battery with small ratio of $\mathrm{W} / \mathrm{D}$, the vapor temperature histories of different fill levels are shown in Fig. 4b. It can
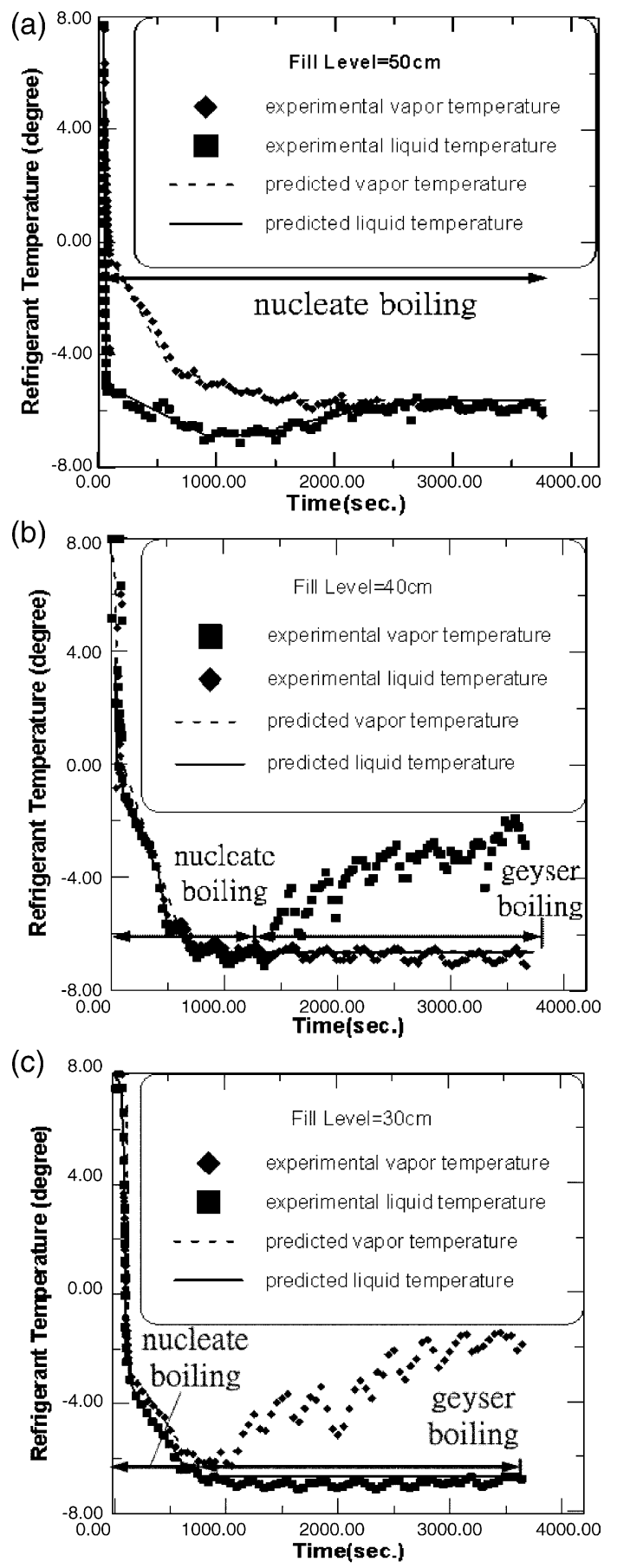

Fig. 5. Liquid and vapor temperature histories for different fill levels: (a) $50 \mathrm{~cm}$, (b) $40 \mathrm{~cm}$, (c) $30 \mathrm{~cm}$. be observed from the figure that the vapor temperature of high fill level drops steeply initially and kept constant afterward. The vapor temperature of low fill level drops steeply in the beginning, then keeps constant for a period, and oscillates and rises periodically. As described above, the heat transfer mechanism in the case of high fill level is nucleate boiling only, while the case of low fill level can be divided into two flow regimes: the first one conformed to nucleate boiling and the secondary one conformed to geyser boiling.

The effects of fill levels on liquid temperatures at the lower header and vapor temperatures at upper location are quantitatively demonstrated in Fig. 5. It is seen that under all operating conditions, the experimental and predicted temperature of both liquid and vapor drops steeply at the beginning. But subsequent experimental and predicted temperature profiles of liquid and vapor variation differ with different fill levels. When the fill level is at $50 \mathrm{~cm}$ as shown in Fig. 5a, both the experimental and predicted liquid temperatures rise from subcooling to operation temperature at the time of $2100 \mathrm{~s}$, while vapor temperature always keeps saturated. Since the cold storage rate in high fill level for entire cold storage process is larger enough for nucleate boiling. Since the heat transfer mechanism during the entire cold storage process is dominated by nucleate boiling, predicted temperature profiles of liquid and vapor show good agreement with experimental measurements.

The vapor and liquid temperature histories for fill levels 30 and $40 \mathrm{~cm}$ are shown in Fig. 5b and c. Experimental data of vapor temperature at the time of 800 and $1300 \mathrm{~s}$ for fill levels of 30 and $40 \mathrm{~cm}$ rises from saturation to superheated vapor. Oscillation of experimental vapor temperature occurs. As for the case of $30 \mathrm{~cm}$ fill level, it can be observed that the experimental vapor temperature becomes more violent than that of $40 \mathrm{~cm}$ fill level. It is obvious that the heat transfer mechanisms in 30 and $40 \mathrm{~cm}$ fill levels change from nucleate boiling

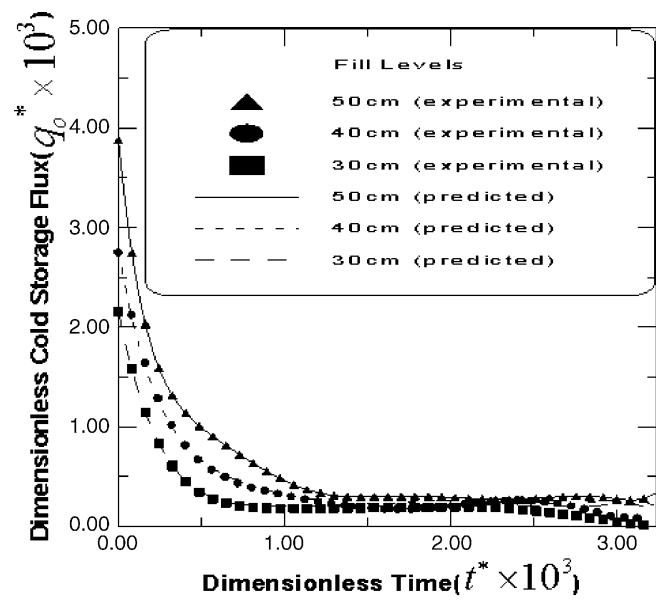

Fig. 6. Dimensionless cold storage flux for different fill levels. 


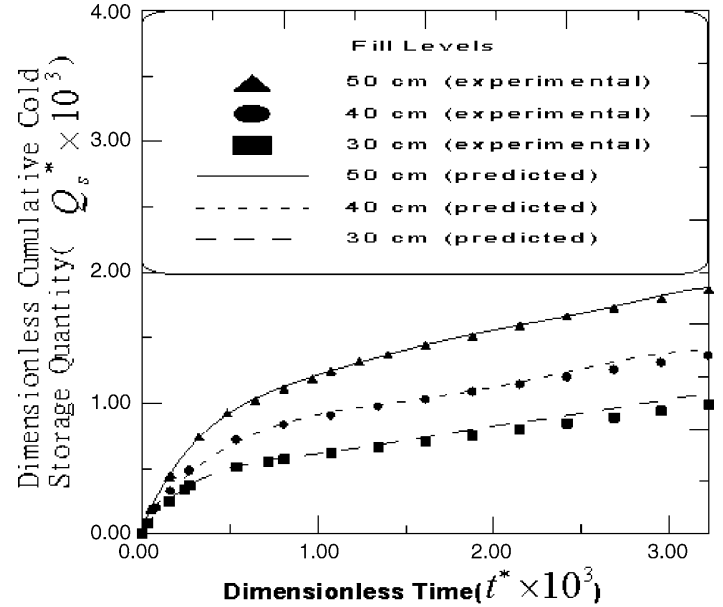

Fig. 7. Dimensionless cumulative cold storage quantity for different fill levels.

to geyser boiling. The reason for these discrepancies between the experimental measurements and the present model is that the present theoretical model is suitable only for nucleate boiling stage. The applicable range for the present model is that the cold storage flux of the thermal battery should be larger than the transition cold storage flux where geyser boiling changes to nucleate boiling.

Niro et al. [8] had conducted experimental study of the boiling mechanism in a two-phase thermosyphon loop. They proposed a correlation at the transition frontier between geyser boiling and nucleate boiling, as a function of critical liquid superheat and fluid thermodynamics properties. It was found that the transition frontier from geyser boiling to nucleate boiling occurs for the Jakob number, ratio of sensible energy to latent energy absorbed during liquid-vapor phase change, is smaller than 7. It means that the present model is only applicable in those ranges.

Fig. 6 depicts the experimental and predicted dimensionless cold storage flux $q_{\mathrm{o}}^{*}$ at the fill level of 50, 40 and $30 \mathrm{~cm}$ respectively. The definition of the dimensionless cold storage flux is:

$q_{\mathrm{o}}^{*}=\left(S_{0}+S_{1}+h_{\mathrm{A}}+h_{\mathrm{EA}}\right) \dot{Q}_{0} /\left(A_{\mathrm{H}} \rho_{\mathrm{F}} v_{\mathrm{F}} h_{\mathrm{fg}}\right)$

The dimensionless time is the product of Fourier number, Fo, and Prandtl number, Pr, which can be written as:

$t^{*}=\mathrm{FoPr}$

Fourier number is the ratio of the heat conduction rate to the rate of thermal energy storage in the thermal battery, and Prandtl number is the ratio of the momentum and thermal diffusivities. It is observed that with the lapse of dimensionless time, the experimental and predicted dimensionless cold storage flux of different fill levels decrease rapidly, then become to flat gradually. But subsequent experimental and predicted dimensionless cold storage flux profiles differ. As the ice layer thickness increases to a certain value (approximate 2.0 $\mathrm{cm}$ ), the dimensionless cold storage flux becomes stable. It also can be seen from this figure that the higher the fill level, the faster the dimensionless cold storage flux. Experimental dimensionless cold storage fluxes decrease to zero earlier with the lower fill level. But the predicted dimensionless cold storage fluxes of different fill level in the last stage nearly keep constant. This is because the present model considers that nucleate boiling is the only heat transfer mechanism during the cold storage process.

Fig. 7 illustrates experimental and predicted dimensionless cumulative cold storage quantity $Q_{\mathrm{s}}^{*}$ versus dimensionless time under different fill levels. The dimensionless cumulative cold storage quantity is the summation of dimensionless cold storage flux for each dimensionless time interval $\Delta t^{*}$ in thermal battery. It is seen from the figure that at any fill level, there appears an initial stage with steep curve slope and a secondary stage flattened gradually both experimentally and predictably. When cold storage ends at $3600 \mathrm{~s}$, the final dimensionless cumulative cold storage quantity for the fill level of 30,40 , and $50 \mathrm{~cm}$ experimentally is $9.83 \times 10^{-4}, 1.36 \times 10^{-3}$, and $1.86 \times 10^{-3}$ (i.e., $4098.51 \mathrm{~kJ}$, $4932.80 \mathrm{~kJ}$, and $6405.19 \mathrm{~kJ})$ respectively, and that numerical prediction is $1.07 \times 10^{-3}, 1.43 \times 10^{-3}$, and $1.89 \times 10^{-3}$ (i.e. $5160.47 \mathrm{~kJ}, 5743.84 \mathrm{~kJ}$, and $6688.32 \mathrm{~kJ}$ ) respectively. It is found that the predicted dimensionless cumulative cold storage quantity of all fill levels is larger than experimental results, and error percentage of predicted result is larger for the case of lower fill level. This is because the larger period of geyser boiling occurred during cold storage process as the fill level is lower, and the predicted dimensionless cold storage flux is larger than experimental dimensionless cold storage flux for geyser boiling stage. It results the final predicted dimensionless cumulative cold storage quantity is larger than the experimental results.

\section{Conclusions}

With larger $\mathrm{W} / \mathrm{D}$, it takes longer for thermal battery to reach full capacity, but the quantity of ice storage is greater. For thermal battery to reach its full capacity at a given interval of time, W/D must be properly designed. It is suggested that the ratio of distance between heat pipes to outer diameter of heat pipe (W/D) be less than 4 . As for the effect of the fill level on thermal battery, if the fill level is higher, the cold storage rate is larger. The time for the heat transfer mechanism period in nucleate boiling is longer, and the cumulative cold storage quantity is larger. Since the present theoretical 
model is only suitable for the nucleate boiling stage, the prediction of cold storage quantity from the present model is overestimated for the geyser boiling or natural convection existed during the cold storage process in the thermal battery.

\section{References}

[1] Dincer I, Rosen MA. Thermal Energy Storage Systems and Applications. London: Wiley; 2001.

[2] Chen SL, Hsiao MJ. Heat pipe circuit type thermal battery. Patent no. US 6,220,337 B1, 2001.

[3] Macdonald TW, Hwang KS, Diciccio R. Thermosyphon loop performance characteristics: part 1. Experimental study. Trans ASHRAE 1977;83:250-9.

[4] Manlio B, Jai P. Transport of thermal energy by a simple two-phase loop. Int J Energy Res 1988;12:679-98.

[5] Chen KS, Shiao YY, Wang PC. An experimental study on steady-state behavior of a two-phase natural circulation loop. Energy Conversion \& Management 1991;31(6):553-9.

[6] ISO. Guide to the expression of uncertainty in measurement [corrected and reprinted 1995].

[7] Bogan H, Gheorghe D, Aristotel P. Mathematical models for the study of solidification within a longitudinally finned heat pipe latent heat thermal storage system. Energy Conversion \& Management 1999;40:1765-74.

[8] Niro A, Beretta GP. Boiling regimes in a closed two phase thermosyphon. Int J Heat Mass Transfer 1990;33(10):2108. 